\title{
Rooting and Other Characteristics of a Transgenic Walnut Hybrid (Juglans hindsii x J. regia) Rootstock Expressing rolABC
}

\author{
Kourosh Vahdati, ${ }^{1}$ James R. McKenna, ${ }^{2}$ Abhaya M. Dandekar, Charles A. Leslie, Sandie L. Uratsu, \\ Wesley P. Hackett, ${ }^{3}$ Paola Negri, ${ }^{4}$ and Gale H. McGranahan ${ }^{5}$ \\ Department of Pomology, University of California, Davis, CA 95616
}

\begin{abstract}
AdDitional INDEX wORDs. Paradox, rooting, difficult-to-root, cuttings, tissue culture
Abstract. Walnuts (Juglans spp.) are difficult-to-root woody plants. The rolABC genes $($ rolA + rolB + rolC $)$, derived from the bacteria Agrobacterium rhizogenes, have been shown to increase the rooting potential of other difficult-to-root woody plants. We inserted the rolABC genes into somatic embryos of a 'Paradox' hybrid (J. hindsii X J. regia) clone PX1 using the A. tumefaciens gene transfer system. A transgenic sub-clone, designated PX1 rolABC 2-2 was selected and compared to the untransformed clone for a variety of phenotypic characteristics, including rooting potential. Transformed and untransformed shoots were budded onto seedling $J$. regia rootstock in the greenhouse and established in the field. Transformed trees displayed reduced internode length, an increase in lateral branching, and wrinkled leaves. In another test, a commercial persian walnut cultivar J. regia 'Chandler' was grafted onto rooted cuttings of both the untransformed and transformed plants. The presence of the rolABC genes in the rootstock had no visible effects on the grafted scion. Several of these trees were excavated from the field and the root systems of each genotype were examined for root number, diameter, and biomass. Trees with the rol $A B C$ rootstock had significantly more small diameter roots compared to the controls and less recovered biomass. Tests of the rooting potential of leafy semi-hardwood cuttings for two years resulted in $14 \%$ to $59 \%$ rooting of the transformed cuttings compared to $51 \%$ to $81 \%$ rooting of the control. Both transformed hardwood cuttings and microshoots in tissue culture also rooted significantly less $(52 \%$ and $29 \%$ respectively) than untransformed hardwood cuttings and tissue cultured shoots ( $82 \%$ and $54 \%$ respectively). Thus, although the rolABC genes induced a shorter internode length and a more fibrous root system (typical of rol-tranformed plants), they were not useful for increasing the rooting potential, and as rootstock they did not affect the phenotype of the scion.
\end{abstract}

'Paradox' walnut, an interspecific hybrid between black walnut (Juglans hindsii Jepson ex R.E. Smith) and persian/english walnut (J. regia L.), is used extensively as a rootstock for persian walnut cultivars in California (McGranahan and Catlin, 1987). Commercial vegetative propagation of walnut rootstocks is uncommon because of difficulties in rooting (Lynn and Hartmann, 1957; McKenna, 1997; Reil et al., 1998; Vahdati, 1996). The interest in rooting cuttings of 'Paradox' has recently increased due to the identification of rootstock selections that are potentially resistant or tolerant of destructive diseases (McGranahan et al., 1998).

Transformation with the rol genes is of interest in many woody species due to their effects on plant development, particularly rooting (Rugini and Mariotti, 1992). Rol genes were originally derived from a T-DNA located on large root-inducing (Ri) plasmids presentinall virulent strains of Agrobacteriumrhizogenes (Costantino et al., 1981). Among the 18 different open reading frames (ORFs) identified on this T-DNA, only four loci, $\mathrm{rol}$ ( $\mathrm{rolA}, \mathrm{rolB}$, rolC and rolD), noticeably affect other attributes of plant growth and development (Slightom et al., 1986). These rol genes have been reported to change the following characteristics in transformed plants: rolA causes wrinkled leaves, condensed inflorescences, increased stigma

Received for publication 10 Jan. 2002. Accepted for publication 10 May 2002. We thank Burchell Nursery Inc. and Corey Barnes for technical assistance, the Walnut Marketing Board of California for funding and the Ministry of Science, Research and Technology of Iran for supporting the stay of Kourosh Vahdati in the U.S. ${ }^{1}$ Present address: Department of Horticultural Sciences, Faculty of Agriculture, University of Tehran, Karaj, Iran.

${ }^{2}$ Present address: USDA Forest Service/Hardwood Tree Improvement and Regeneration Center, Purdue University, West Lafayette, IN 47907.

${ }^{3}$ Present address: Department of Environmental Horticulture, University of California, Davis, CA 95616.

${ }^{4}$ Present address: Dipartimento di Colture Arboree, CAAB, via Fanin 40, 40100 Bologna, Italy.

${ }^{5}$ Corresponding author: e-mail: ghmcgranahan@ucdavis.edu. size and larger flowers; rolB increases rooting potential which may result from increased auxin sensitivity of the tissues, alters leaf morphology and increases flower size; rolC reduces internode length, produces flowering abnormalities, and increases branching; and, rolD causes dwarfing and early flowering (Rugini et al., 1997; Schmulling et al., 1988; Scorza et al., 1994).

The interest in genetic transformation of plants with rol genes as a potential means to enhance rooting competence is based on experiments that showed that Agrobacterium rhizogenes when applied to the base of micro and conventional stem cuttings increased adventitious rooting for several species (Caboni et al., 1996; Damiano and Monticelli, 1998; Rugini and Mariotti, 1992; Tzfira et al., 1998). Caboni et al. (1996) showed that A. rhizogenes applied to the base of microcuttings of persian walnut induced $58 \%$ rooting on hormone-free medium and $62.9 \%$ rooting in the presence of indolebutyric acid (IBA) while those treated with IBA alone did not root. In addition, it has been observed in several species that plants that have been genetically transformed with constructs containing single or multiple rol genes exhibit enhanced adventitious root initiation (DiCola et al., 1996; Rugini et al., 1991; van der Salm et al., 1996, 1997; Welander et al., 1998).

The primary objective of this work was to determine the effect of rolABC genes on walnut rootability. Several rooting trials were conducted using semi-hardwood cuttings, hardwood cuttings and tissue cultured shoots of a transformed and untransformed 'Paradox' clone. Because expressing these three genes in the plants could alter other traits such as vigor, lateral branching and root architecture, shoot and root characteristics of the transgenic walnut trees were also examined.

\section{Material and Methods}

VECTOR CONSTRUCTION AND TRANSFORMATION CONFIRMATION. A 
vector was constructed containing the rolABC genes from Agrobacterium rhizogenes strain A4 by using subclones of the TRDNA of pRiA4. The rolABC region was obtained as a $4.3-\mathrm{kb}$ $E c o$ RI fragment. This fragment was purified by gel electrophoresis and subcloned into pBluescript, creating a plasmid designated pDN152 (containing the rolABC genes regulated by their native promoters). In addition, we subcloned a gene cassette containing an intron containing the GUS gene (35SGUS-INT) into pBluescript creating plasmid pDN352 (containing 35SGUS-INT). The GUS gene from $\mathrm{pDN} 352$ and the rolABC fragment from $\mathrm{pDN} 152$ were introduced into the binary vector $\mathrm{pBIN} 19$ to create the new vector pDN3514, the details of which have been described by Negri (1992).

For Southern blots, DNA was isolated from $100 \mathrm{mg}$ of young leaf tissue using the Qiagen DNeasy Plant Kit (Valencia, Calif.). About $4 \mu \mathrm{g}$ of each DNA sample was digested with the restriction endonuclease HindIII as described by the manufacturer (Gibco BRL). Digested fragments of walnut genomic DNA were separated via electrophoresis on a $0.8 \%$ agarose gel, transferred to a nylon membrane by Southern blotting (Sambrook et al., 1989), and UV cross-linked. The coding sequence of rolABC was obtained by digestion of pDn152 with EcoR 1 and isolating the 4.3-kb fragment. This fragment was labeled with digoxigerin- $\mathrm{d}$ UTP using Roche Molecular Biochemicals Genius Kit (Indianapolis, Ind.) and used as a probe.

Blots were prehybridized for $4 \mathrm{~h}$ at $65^{\circ} \mathrm{C}$ and hybridized for 16 to $24 \mathrm{~h}$ at the same temperature to the labeled probe. The blots were washed at $65^{\circ} \mathrm{C}$ in $0.1 \times \mathrm{SSC}, 0.1 \% \mathrm{SDS}$. The hybridization was detected by chemiluminescent detection as described by Boehringer Mannheim. Images of the hybridization were obtained by exposure of the blots to X-ray film for 2 to $5 \mathrm{~h}$ at room temperature.

RNA for RT-PCR was isolated from $100 \mathrm{mg}$ of tissue (embryos or young leaves) using Qiagen RNeasy Plant Mini Kit (Valencia). RT-PCR was carried out according to Promega (Madison, Wis.) using their Access RT-PCR system and total RNA as template. The sequences for the primers were derived from Slightom et al. (1986).

Plant material. Immature open-pollinated seed of $J$. hindsii 'Rawlins' were collected in June, surface sterilized, and the excised cotyledons were cultured to produce somatic embryos (Tulecke and McGranahan, 1985). Repetitively embryogenic cultures were maintained and individual embryos were germinated to identify hybrids. Hybrids between J. hindsii and J. regia were identified based on bud position (Jay-Allemand et al., 1990). Somatic embryos from one of these hybrid clones, designated 'PX1', were inoculated with engineered Agrobacterium tumefaciens as described by McGranahan et al., 1990, and a transgenic subclone, designated 'PX1 rolABC (2-2)' was retrieved. Shoot cultures of the control (PX1) and the transgenic line were developed and buds of the in vitro shoots were budded onto seedling $J$. regia rootstock in the greenhouse. The budded plants were transplanted to the field the following year (1996). Three trees of each were maintained for descriptive purposes, and one to three other trees of each served as a source of cuttings. Those designated for cuttings were severely pruned annually. The remaining trees were left unpruned in 1999 and 2000 so that the phenotype could be described in 2001.

Rooted cuttings of both transformed and untransformed PX1 were produced in 1997 and grown in the field in 1998 at Burchell Nursery Inc, Oakdale, Calif. Trees were dug in the winter, planted at the University of California, Davis, in 1999 and grafted with scions of the $J$. regia cultivar Chandler in 2000. These trees were used to describe the effects of the rolABC genes present in the rootstock on both the transgenic root system and the nontransgenic scion.

Rooting STUDIEs. Leafy semi-hardwood cuttings were collected early in the morning from the severely pruned stock plants in 1997 and 1998. Three-node cuttings of current-year shoots with a stem diameter of 10 to $15 \mathrm{~mm}$ and 10 to $20 \mathrm{~cm}$ in length were made. In 1997, cuttings were collected 27 Aug. and three replications of 36 cuttings of both the untransformed and transformed genotypes were treated with the auxin potassium indole3-butyric acid, (K-IBA; Sigma Chemical Corp, St. Louis, Mo.) at an optimized concentration of $8,000 \mathrm{mg} \cdot \mathrm{L}^{-1}$ (Lynn and Hartmann, 1957; McKenna, 1997) and applied as a 30-s quick dip. Cuttings were stuck in individual solid-block-media sponges (Growtech Inc., San Juan Bautista, Calif.) and arranged on a mist bench in a completely randomized design. Cuttings were misted with deionized water for $15 \mathrm{~s}$ every $4 \mathrm{~min}$ during daylight hours. Bottom heat was supplied by heating mats at $24 \pm 5^{\circ} \mathrm{C}$.

The time-course for rooting semi-hardwood cuttings was investigated in 1997 by observing cuttings for rooting beginning $19 \mathrm{~d}$ after sticking (DAS) and then about every $3 \mathrm{~d}$ afterwards until day 56. A cutting was scored as rooted when at least one adventitious root protruded through the sponge. Three experiments, arranged as completely randomized designs with three replications of each rootstock were conducted beginning on 19 Aug., 27 Aug., and 4 Sept. 1997. The time-course for rooting was determined by averaging the mean rooting percentage of each rootstock within a range of 2 to 4 DAS across the three experiments. Thus, DAS values are an average of the two to four values among each of the three experiments and the standard deviations presented are pooled among the three experiments. In 1998, the same experiment was repeated only on July 11 th with an additional water-only control treatment.

Hardwood cuttings, 12 to $18 \mathrm{~cm}$ long, containing at least three nodes were taken from dormant 1-year-old shoots in February 2001. A range of auxin (K-IBA) concentrations was tested (in $\mathrm{mg} \cdot \mathrm{L}^{-1}$ ): 8,000, 4,000, 2,000, and 0 (water control). For each treatment, there were four replications of fifteen cuttings. Cut-

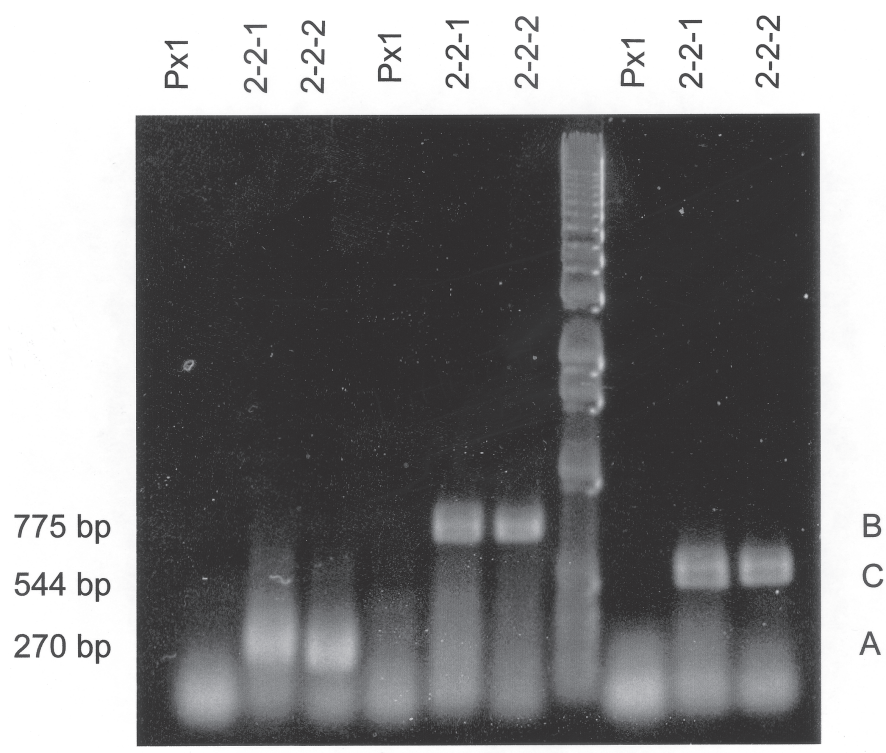

Rol RT PCR of Walnut Leaves

Fig. 1. RT-PCR analysis of rolABC gene expression in walnut leaves. 
tings were stuck in sponges and placed outdoors in a lathhouse on heating mats set at $30 \pm 2{ }^{\circ} \mathrm{C}$. Rooting percent was determined 60 DAS by scoring all cuttings with at least one visible adventitious root as rooted. Each cutting was then assigned to one of three quality classes based on the number of roots per cutting.

Tissue-cultured shoots of transformed and untransformed plants were tested for rooting in vitro. Shoots were derived from the somatic embryo lines described above that had been established in 1996, and maintained in culture following the methods of McGranahan et al. (1988). Thirty-two shoots, 3 to $4 \mathrm{~cm}$ in length, of each genotype were treated for rooting following the methods of Jay-Allemand et al. (1992).

SHOOT AND ROOT CHARACTERISTICS. Shoot characteristics (length of 1-year shoots, number of nodes per shoot, and number of lateral branches per shoot) were measured on four randomly selected 1year-old shoots from each of three trees grafted with scions of either PX1 or PX1 rolABC. Shoots similar in canopy position on both genotypes were selected. Length of 1-year old shoots was recorded. The number of nodes and lateral branches were counted on $1 \mathrm{~m}$ shoot segments, $25 \mathrm{~cm}$ above the base of the shoot. Similar measurements were taken on the 'Chandler' scions grafted on the control and transgenic rootstock.

Root systems of trees originating from rooted cuttings of PX1 and PX1 rolABC and grafted with scions of J. regia 'Chandler' were examined. Three trees of each type were excavated with a backhoe for determination of root biomass and root architecture. Following excavation, root systems were washed and photographed. Then, all recovered roots $20 \mathrm{~cm}$ below the crowns were dissected, assigned a diameter class (1 to 5), and the dry weight of the roots within each class was determined.

\section{Results and Discussion}

MoleCUlar ANALYSIS. Southern analysis of the transformed lines showed the expected internal 1.8 -kb fragment that hybridized with the rolABC probe and a single border fragment indicating a single insertion event. The control PX1 showed no hybridization with the rolABC probe. RT-PCR analysis of $1 \mu \mathrm{g}$ of total RNA from embryos indicated the presence of rolA (270 bp), rolB (775 bp) and rolC (544 bp). In leaves, the same result was obtained with $100 \mathrm{ng}$ of total RNA (Fig. 1).

SHOOT AND ROOT CHARACTERISTICS. Field-grown rolABC and PX1 control trees, both grafted on J. regia rootstock, reached the same height (Fig. 2), but clearly differed in canopy phenotype. The transgenic trees had denser and bushier foliage, with wrinkled and slightly curled leaves. They also had more nodes, shorter internodes, and more branches per meter (Table 1). Shoot elongation was delayed during the normal spring growth period in the transgenic trees but continued later into the summer. By fall, trees had roughly equivalent growth but the transgenic trees were delayed entering fall dormancy. Their leaves were still green after the control's had turned yellow, and leaf abscission also occurred later. Delayed dormancy in the transgenic trees resulted in branch tip die-back in an early frost year (2001). Although internodes were shortened, a dwarfed phenotype that would be of interest as a rootstock was not conferred by the rolABC genes.

Examination of 'Chandler' scions grafted on the rolABC and PX1 rootstock showed no difference in number of nodes (15 to 17) per meter of shoot measured from $25 \mathrm{~cm}$ above the graft union (data not shown). Trunk circumference and leaf appearance were also similar on both rootstocks and typical of 'Chandler'. These findings indicate that the transgenic rootstock had no discernible effect on the scion. To our knowledge this is the first report of the lack of influence of a rolABC transformed rootstock on a nontransformed scion cultivar.

The root architecture of the transgenic rootstock, however, was clearly different from that of the control (Fig. 2). Roots of the rolABC rootstock were fibrous with few roots over $15 \mathrm{~mm}$ diameter. Consequently, although there was a significantly greater number of roots recovered from the transgenic rootstock, the root dry weight was significantly less than that of the PX1 control
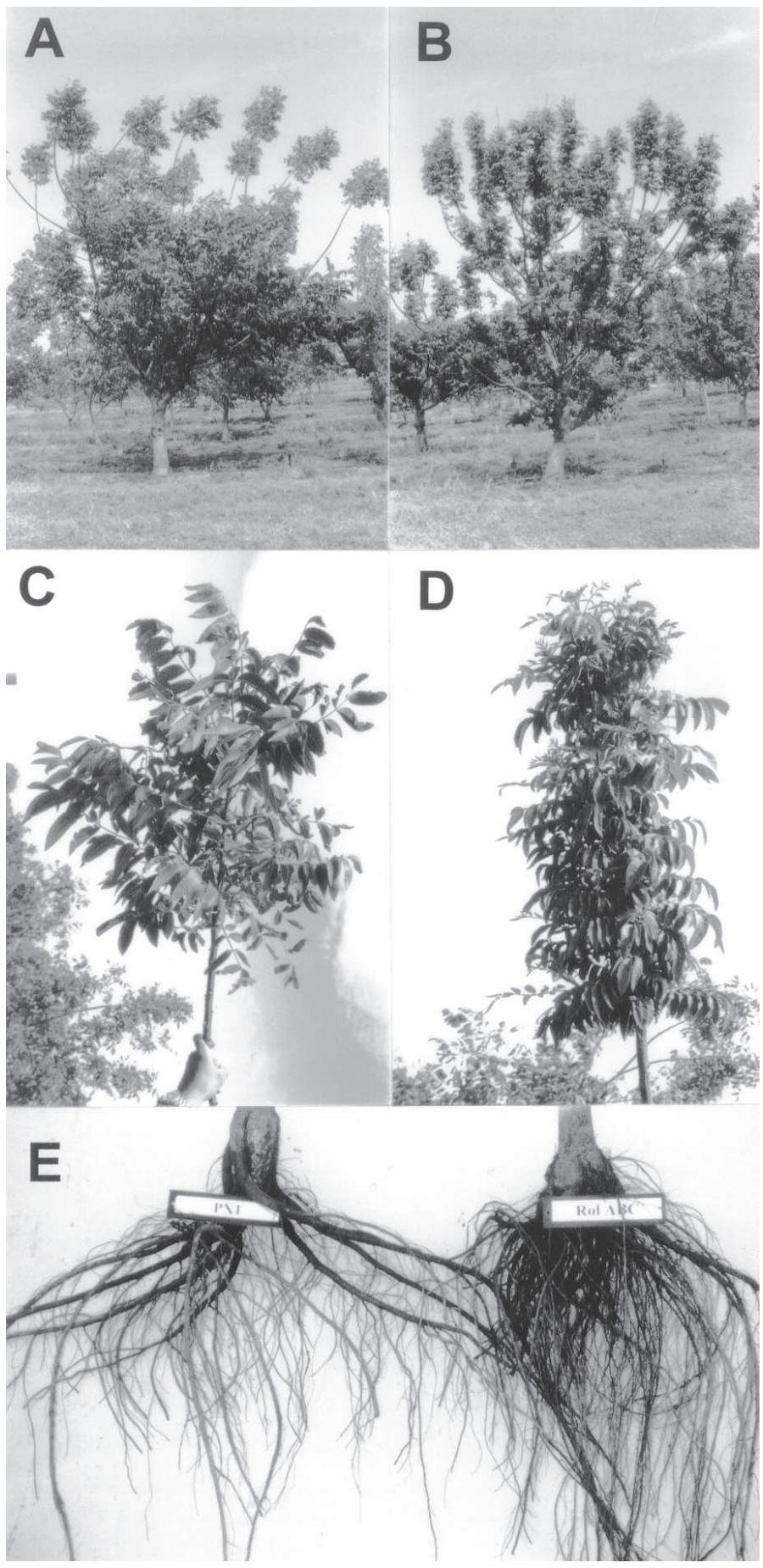

Fig. 2. Morphological characteristics of Paradox (PX1) untransformed control [A, $\mathbf{C}$, and $\mathbf{E}$ (left)] and trees transformed with rolABC genes $(\mathbf{B}, \mathbf{D}$, and $\mathbf{F}) ;(\mathbf{A}$ and B) 5-year-old trees in the field; (C and D) 1-year-old shoots illustrating compressed internode length of rolABC trees; (E) 4-year-old field-grown root systems showing greater number of small-diameter roots on the rolABC trees. 
Table 1. Characteristics of shoots and roots of own-rooted rolABC 'Paradox' walnut trees compared to the untransformed PX1 control.

\begin{tabular}{|c|c|c|c|c|c|c|c|c|c|c|c|}
\hline \multirow[b]{4}{*}{ Genotype } & \multicolumn{4}{|c|}{ Shoot system $^{z}$} & & & & & & & \\
\hline & \multirow{3}{*}{$\begin{array}{l}\text { Leaf } \\
\text { surface }\end{array}$} & \multirow{3}{*}{$\begin{array}{c}\text { Length of } \\
\text { 1-year } \\
\text { shoots } \\
(\mathrm{cm})\end{array}$} & \multirow{3}{*}{$\begin{array}{c}\text { No. of } \\
\text { lateral } \\
\text { branches } \\
\left(\mathrm{M}^{-1}\right)\end{array}$} & \multirow{3}{*}{$\begin{array}{c}\text { No. of } \\
\text { nodes } \\
\left(\mathrm{M}^{-1}\right)\end{array}$} & \multicolumn{7}{|c|}{ Root system ${ }^{y}$} \\
\hline & & & & & \multicolumn{5}{|c|}{ No. of roots/class $(\mathrm{mm})$} & \multirow{2}{*}{$\begin{array}{c}\text { Total } \\
\text { no. of } \\
\text { roots }\end{array}$} & \multirow{2}{*}{$\begin{array}{c}\text { Root } \\
\text { dry wt } \\
(\mathrm{g})\end{array}$} \\
\hline & & & & & $0.1-1$ & $1-5$ & $5-15$ & $15-30$ & $>30$ & & \\
\hline PX1 (control) & Smooth & $168 \pm 11$ & $17 \pm 4$ & $32 \pm 4$ & 10 & 9 & 7 & 6 & 2 & 34 & $488 \pm 65$ \\
\hline $\operatorname{rol} A B C$ & Wrinkled & $157 \pm 7$ & $29 \pm 3$ & $52 \pm 1$ & 51 & 34 & 22 & 3 & 0 & 110 & $229 \pm 77$ \\
\hline
\end{tabular}

${ }^{\mathrm{z}}$ Shoot characteristics were determined on 5-year-old grafted field grown trees that had not been pruned for 2 years. Values are averages based on 4 shoots measured on each of 3 trees \pm SD.

${ }^{y}$ Root characteristics are based on 4-year-old field grown cuttings. Values are the average of 3 trees \pm SD.

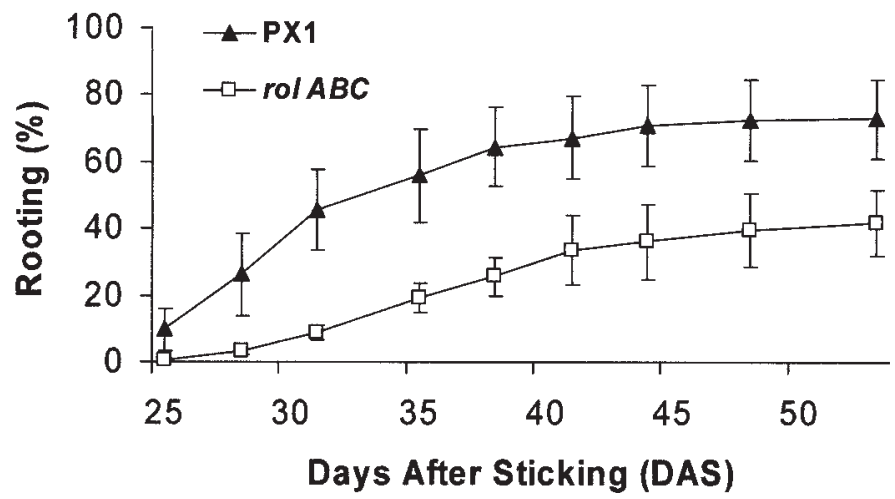

Fig. 3. Rooting percent of untransformed (PX1) and transformed (rolABC) Paradox semi-hardwood cuttings over time in 1997. Values represent the average of three experiments \pm pooled SD.

Table 2. Rooting of untransformed and transformed 'Paradox' walnut semi-hardwood cuttings treated with or without auxin.

\begin{tabular}{lccc}
\hline \hline Genotype & $\begin{array}{c}\text { Auxin } \\
\left(\mathrm{mg} \cdot \mathrm{L}^{-1}\right)\end{array}$ & $\begin{array}{c}\text { Rooting } \\
(\%)\end{array}$ & $\begin{array}{c}\text { No. rooted/ } \\
\text { no. stuck }\end{array}$ \\
\hline PX1 & 8,000 & 81 & $87 / 108$ \\
& 0 & 26 & $22 / 86$ \\
RolABC & 8,000 & 14 & $15 / 108$ \\
& 0 & 6 & $5 / 99$ \\
\hline
\end{tabular}

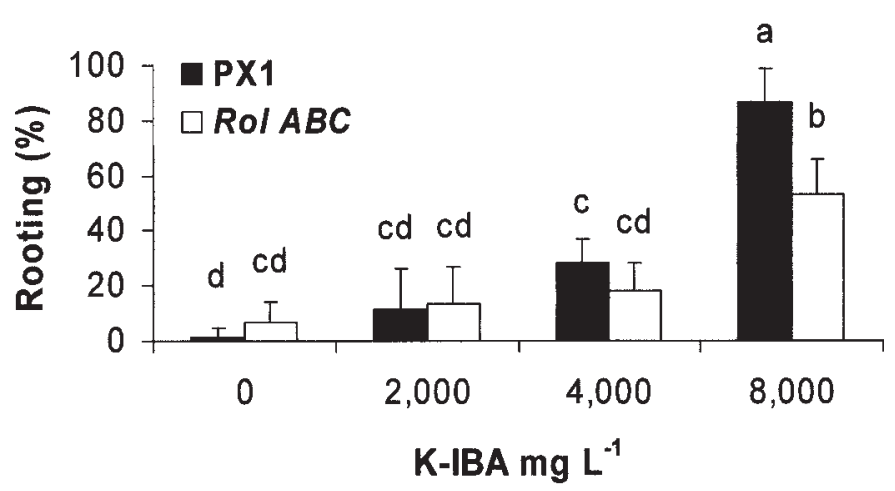

Fig 4. Rooting of Paradox control (PX1) and transformed Paradox (rolABC) hardwood cuttings treated with different auxin (K-IBA) concentrations. Values are the average of 4 replications of 15 cuttings \pm SE stuck in early February 2001. rootstock (Table 1). The characteristics of these 'Paradox' trees transformed with $\operatorname{rolABC}$ are consistent with the characteristics of other species transformed with single or multiple rol genes (Rugini et al., 1992; Schmulling et al., 1988; Scorza et al., 1994; Welander et al., 1998).

ROOTING LEAFY SEMI-HARDWOOD CUTTINGS. As shown in Fig. 2 , walnut semi-hardwood cuttings started to root $25 \mathrm{DAS}$, and rooting percentage plateaued by $\approx 45$ DAS. At 56 DAS, $73 \%$ $( \pm 20)$ of the control PX1 cuttings had rooted compared to only $42 \%( \pm 17)$ of transformed rolABC cuttings. In 1998, nontransformed and transformed cuttings rooted $81 \%$ and $14 \%$ respectively (Table 2). In the water-only control treatment PX1 cuttings rooted better than transformed ones.

ROOTING DORMANT HARDWOOD CUTTINGS. Increasing K-IBA concentrations increased rooting percentage in dormant hardwood cuttings from both transformed and nontransformed clones but the response was greater in the nontransformed clone. The greatest difference was seen at $8000 \mathrm{mg} \cdot \mathrm{L}^{-1} \mathrm{IBA}$ (Fig. 4). These results do not support the hypothesis that $r o l$ genes increase the sensitivity to auxin for root initiation but instead suggest that rol $\mathrm{ABC}$ transformed 'Paradox' cuttings have a reduced ability to respond to auxin for rooting.

Rooting TISSUE CUlTURE SHOOTS. Shoots of the PX1 control clone rooted more frequently and with greater root number than shoots from the rolABC-transformed clone (Table 3). Roots had about the same diameter in both clones, but roots were longer in transformed shoots (Fig. 5). Although rolABC shoots had longer roots, the roots had a looser connection to their shoots and none of the rooted rolABC shoots survived transplanting and acclimatization in the greenhouse.

These results, in which transformation with rolABC has a negative influence on rooting percentage of 'Paradox' cuttings, is in contrast to research results from several other species (Rugini and Mariotti, 1992; Rugini et al., 1991; Van der Salm et al., 1996, 1997). The reason for the observed negative effect of rolABC on rooting of 'Paradox' cuttings is not known. Additional studies to determine the relationship between rolABC expression levels and auxin metabolism could help to clarify this issue.

In conclusion, although there were distinct differences in growth habit of shoots and roots due to insertion of rolABC, the rooting ability of this 'Paradox' clone was not improved by insertion of these genes and the transgenic 'Paradox' rootstock

Table 3. Rooting of tissue-cultured untransformed and transformed 'Paradox' walnut shoots in vitro.

\begin{tabular}{|c|c|c|c|c|c|}
\hline Genotype & $\begin{array}{c}\text { Rooting } \\
(\%)\end{array}$ & $\begin{array}{l}\text { No. of roots/ } \\
\text { rooted cuttings }\end{array}$ & $\begin{array}{l}\text { Root diam } \\
\quad(\mathrm{mm})\end{array}$ & $\begin{array}{l}\text { Longest root } \\
\text { length }^{\mathrm{z}}(\mathrm{mm})\end{array}$ & $\begin{array}{c}\text { Avg root } \\
\text { length }(\mathrm{mm})\end{array}$ \\
\hline$\overline{\mathrm{PX} 1}$ & 54 & $4.3 \pm 3.7$ & $1.8 \pm 0.6$ & $40 \pm 21$ & $29 \pm 15$ \\
\hline rolABC & 29 & $2.0 \pm 1.1$ & $2.0 \pm 0.8$ & $67 \pm 35$ & $49 \pm 36$ \\
\hline
\end{tabular}

${ }^{\mathrm{z}}$ Values are based on average of 32 shoots \pm SD. 




system. Plant Cell Rpt. 8:512-516.

McGranahan, G.H., C.A. Leslie, H.A. Phillips, and A.M. Dandekar. 1998. Genetic improvement. P16-22 In: D.E. Ramos (ed.). Univ. Calif. Walnut Prod. Manual. Publ. 3373.

McKenna, J.R. 1997. Clonal propagation of Paradox walnut rootstocks by conventional methods. MS thesis. University of California, Davis.

Negri, P. 1992. Transferimento di geni rol di Agrobacterium rhizogenes a piante arboree. $\mathrm{PhD}$ diss. Universita' Degli Studi Di Bologna, Italy. Reil, W.O., C.A. Leslie, H.I. Forde, and J.R. McKenna. 1998. Propagation, p. 71-83. In: D.E. Ramos (ed.). Univ. Calif. Walnut Prod. Manual. Publ. 3373.

Rugini,E., G. Caricato, M. Muganu, C. Taratufolo, M. Camilli, C. Cammilli, and A. Altman. 1997. Genetic stability and agronomic evaluation of six-year-old transgenic kiwi plants for rolABC and rolB genes. Acta Hort. 447:609-610.

Rugini, E. and D. Mariotti. 1992. Agrobacterium rhizogenes T-DNA genes and rooting in woody

Fig 5. In-vitro rooting of Paradox control (PX1) and transformed Paradox (rolABC) microcuttings.

did not affect the phenotypic characteristics of the persian walnut scion, suggesting that the alterations in the shoot morphology were not graft transmissible.

\section{Literature Cited}

Caboni, E., P. Lauri, M. Tonelli, G. Falasca, and C. Damiano. 1996. Root induction by Agrobacteriumrhizogenes in walnut. Plant Science 118:203208.

Costantino, P., M.L Mauro, G. Micheli, G. Risuleo, P.J.J. Hooykaas, and R. Schilperoort. 1981. Fingerprinting and sequence homology of plasmids from different virulent strains of Agrobacterium rhizogenes. Plasmids 5:170-182.

Damiano, C. and S. Monticelli. 1998. In vitro fruit trees rooting by Agrobacterium rhizogenes wild type infection. Elec. J. Biotechnol. 1(3):15 Dec.

Di Cola, A., P. Costantino, and L. Spano. 1996. Cell commitment and rolB gene expression in the induction of root differentiation. Plant Cell Tissue Organ Cult. 46:203-209.

Jay-Allemand, C., J. Dufour, and E. Germain. 1990. Detection precoce et rapide des noyers hybrids interspecifiques (Juglans nigra $\times$ Juglans regia) au moyen de criteres morphologiques. P.H.M. Rev. Hort. 311:3941

Jay-Allemand, C., P. Capelli, and D. Cornu. 1992. Root development of in vitro hybrid walnut microcuttings in a vermiculite-containing gelrite medium. Scientia Horti. 51:335-342.

Lynn, C. and H. Hartmann. 1957. Rooting cuttings under mist. Calif. Agr. (May):11-15.

McGranahan, G.H. and P.B. Catlin. 1987.Juglans rootstocks, p. 411-450. In: R.C. Rom and R.F. Carlson (eds.). Rootstocks for fruit crops. Wiley, New York.

McGranahan, G.H., C.A Leslie, and J. Driver. 1988. In vitro propagation of mature persian walnut cultivars. HortScience 23:220.

McGranahan, G.H., C.A. Leslie, S.L. Uratsu, and A.M. Dandekar. 1990. Improved efficiency of the walnut somatic embryo gene transfer species. Acta Hort. 300:301-308.

Rugini, E., A. Pellegrineschi, M. Mencuccini, and D. Mariotti. 1991. Increase of rooting ability in the woody species kiwi (Actinidia deliciosa A. Chev.) by transformation with Agrobacterium rhizogenes rol genes. Plant Cell Rpt. 10:291-295.

Sambrook, J., E. F. Fritsch and T. Maniatis. 1989. Molecular cloning: A laboratory manual. $2^{\text {nd }}$ ed. Cold Spring Harbor Press, Cold Spring Harbor, N.Y.

Schmulling, T., J. Schell, and A. Spena. 1988. Single genes from Agrobacterium rhizogenes influence plant development. EMBO 7:26212629.

Scorza, R., T.W.Zimmerman, J.M. Cordts, and K.J Footen. 1994. Horticultural characteristics of transgenic tobacco expressing the rolC gene from Agrobacterium rhizogenes. J. Amer. Soc. Hort. Sci. 119:1091-1098.

Slightom, J.L., M. Durant-Tardif, L. Juanin, and D. Tepfer. 1986. Nucleotide sequence analysis of TL-DNA of Agrobacterium rhizogenes agropine type plasmid: Identification of open reading frames. J. Biol. Chem. 261:108-121.

Tulecke W. and G.H. McGranahan. 1985. Somatic embryogenesis and plant regeneration from cotyledones of walnut, Juglans regia L.Plant Sci. 40:57-63.

Tzfira, T., B. Vinocur, A. Altman, and A. Vainstein. 1998. rol-Transgenic Populus tremula: Root development, root-borne bud regeneration and in vitro propagation efficiency. Trees 12:464-471.

Van der Salm, T.P.M., C.J.G. van der Toorn, C.H. Hanisch ten Cate, W.M. van der Krieken, and H.J.M. Dons. 1996. The effects of exogenous auxin and rol genes on root formation in Rosa hybrida L. 'Moneyway'. Plant Growth Regulat. 19:123-131.

Van der Salm, T.P.M., C.J.G. van der Toorn, R. Bouwer, C.H. Hanisch ten Cate, and H.J.M. Dons. 1997. Production of ROL gene transformed plants of Rosa hybrida L. and characterization of their rooting ability. Mol. Breeding 3:39-47.

Vahdati K., Khalighi A., 1996. An investigation on different aspects of vegetative propagation of persian walnut. MS thesis. Univ. Tehran, Karaj, Iran.

Welander M., N. Pawlicki, A. Holefors, and F. Wilson. 1998. Genetic transformation of the apple rootstock M26 with the rolB gene and its influence on rooting. J. Plant Physiol. 153:371-380. 